\title{
Prevalence of intestinal parasitic infections among primary school attending students in Barandooz-Chay rural region of Urmia, West Azerbaijan province, Iran in 2008
}

\author{
Khosrow Hazrati Tappe ${ }^{1}$, Habib Mohammadzadeh ${ }^{1}$, Shahla Khashaveh ${ }^{1}$, Baratali Rezapour ${ }^{2}$ \\ and Afshin Barazesh ${ }^{3 *}$ \\ ${ }^{1}$ Department of Parasitology and Mycology, Faculty of Medicine, Urmia University of Medical Sciences, Urmia, Iran. \\ ${ }^{2}$ Department of Environmental Health, Faculty of Public Health, Urmia University of Medical Sciences, Urmia, Iran. \\ ${ }^{3}$ Department of Microbiology and Parasitology, Faculty of Medicine, The Persian Gulf Tropical and Infectious Diseases \\ Research Center, Bushehr University of Medical Sciences, P. O. Box 3631, Bushehr, Iran.
}

Accepted 1 March, 2011

\begin{abstract}
Duplicate stool specimens from 405 primary school attending students of Barandooz-Chay region of Urmia district were tested for intestinal parasites. Besides, duplicate scotch tape slides were obtained and examined microscopically for Enterobius vermicularis and Taenia sp. eggs. A questionnaire containing demographic data was filled for every case, and the relationship between them and the parasitic infection was assayed. Overall, intestinal parasitic prevalence was $42.5 \%$. Prevalence of Giardia lamblia, Entamoeba coli, Blastocystis hominis, Iodamoeba butschlii, Enterobius vermicularis and Hymenolepis nana was 20.5, 14.6, 13.3, 2.5, 10.6 and $0.2 \%$, respectively. No statistic relation was proved between these infections, having tap water facility at home or family population (except for $E$. vermicularis), but there was a significant relationship between parents' education level and family population. According to relatively high prevalence of parasitic infections in the study field, it is necessary to increase hygienic and educational measures.
\end{abstract}

Key words: Prevalence, intestinal parasites, primary school, Urmia.

\section{INTRODUCTION}

Intestinal parasitic infections are still a serious public health problem in the world. It is estimated that some 3.5 billion people are affected, and 450 million are ill as a result of these infections, the majority being children (WHO, 1998). The high prevalence in children is attributed to many factors, particularly the social and economical situation of the individuals, which is the important cause of the prevalence of intestinal parasites, in addition to environmental, poor sanitary and personal hygiene (Scolari et al., 2000).

As a result of the epidemiologic studies during the last

${ }^{*}$ Corresponding author. E-mail: afshin914@gmail.com Tel: +98917-1860724. years in Iran, the high prevalence of intestinal parasites in school children have been widely reported in many areas (Fallah et al., 2004; Hazrati et al., 2006).

The aim of this study was to determine the prevalence of intestinal parasitic infections in Urmia city from 7 to 14 year old school children and its relation to the education of parents, age, family and environmental factors related to intestinal infections.

\section{MATERIALS AND METHODS}

The design used for the study was a cross-sectional design. This study was conducted at nine primary schools, chosen by randomized cluster sampling, from urban areas of Urmia city (the capital of West Azerbaijan province), located in the Northwest of Iran. The sample size was calculated on a prevalence of $40 \%$ 
Table 1. Number of family members and education of parents' related prevalence of intestinal parasitic infections.

\begin{tabular}{|c|c|c|c|c|}
\hline Number of family members & 3 & 4 & 5 & 6 and more \\
\hline$\%$ prevalence of intestinal parasitic infection & 39.6 & 43 & 38.2 & 50 \\
\hline Education of father & $\begin{array}{c}\text { No } \\
\text { education }\end{array}$ & $\begin{array}{c}\text { Primary } \\
\text { school }\end{array}$ & $\begin{array}{l}\text { Secondary } \\
\text { school }\end{array}$ & $\begin{array}{l}\text { High school } \\
\text { and more }\end{array}$ \\
\hline$\%$ prevalence of intestinal parasitic infection & 49 & 44.7 & 41.7 & 32.1 \\
\hline Education of mother & $\begin{array}{c}\text { No } \\
\text { education }\end{array}$ & $\begin{array}{c}\text { Primary } \\
\text { school }\end{array}$ & $\begin{array}{l}\text { Secondary } \\
\text { school }\end{array}$ & $\begin{array}{l}\text { High school } \\
\text { and more }\end{array}$ \\
\hline$\%$ prevalence of intestinal parasitic infection & 44.3 & 43.3 & 42.7 & 30 \\
\hline
\end{tabular}

Table 2. Number of family members and related education of fathers and mothers.

\begin{tabular}{|c|c|c|c|c|c|c|c|c|c|}
\hline \multirow{3}{*}{ Education of father } & \multicolumn{9}{|c|}{ Number of family members } \\
\hline & \multicolumn{2}{|c|}{3} & \multicolumn{2}{|c|}{4} & \multicolumn{2}{|c|}{5} & \multicolumn{2}{|c|}{6} & \multirow{2}{*}{ Tota } \\
\hline & $\mathrm{n}$ & $\%$ & $\mathbf{n}$ & $\%$ & $\mathbf{n}$ & $\%$ & $\mathbf{n}$ & $\%$ & \\
\hline No education & 5 & 8.5 & 17 & 28.8 & 17 & 28.8 & 20 & 33.9 & 59 \\
\hline Primary school & 21 & 9.7 & 102 & 47 & 52 & 24 & 42 & 19.4 & 217 \\
\hline Secondary school & 12 & 12.5 & 63 & 65.6 & 19 & 19.8 & 2 & 2.1 & 96 \\
\hline High school and more & 10 & 33.3 & 17 & 56.7 & 1 & 3.3 & 2 & 6.7 & 30 \\
\hline \multicolumn{10}{|l|}{ Education of mother } \\
\hline No education & 6 & 12.2 & 16 & 32.7 & 9 & 18.4 & 18 & 36.7 & 49 \\
\hline Primary school & 17 & 9 & 85 & 45.2 & 45 & 23.9 & 41 & 21.8 & 188 \\
\hline Secondary school & 14 & 13 & 63 & 58.3 & 27 & 25 & 4 & 3.7 & 108 \\
\hline High school and more & 11 & 19.6 & 36 & 64.3 & 8 & 14.3 & 1 & 1.8 & 56 \\
\hline
\end{tabular}

$d=0.05$, at a confidence level of $95 \%$. So, the calculated study population size was 405 . The school lists, for all children in grade one to four, in all nine primary schools in Urmia city were prepared. A total of 405 primary school children were randomly selected from the lists of nine schools. The questionnaire contained age, gender, residence, education and occupation of parents, number of family and water supply. Stool samples of each student were collected in labeled plastic vials without preservatives. They were examined for intestinal parasites by wet mount and formalin-ether sedimentation techniques, and cellophane tape was used to detect Enterobius vermicularis infection. Data were analyzed using SPSS 11 for windows pocket program.

\section{RESULTS}

The subjects consisted of $246(60.7 \%)$ boys and 159 $(39.3 \%)$ girls, aged between 6 and 12 years. In all, 172 students $(42.5 \%)$ were infected with one or more intestinal parasites. The most common was Giardia lamblia [83 (20.5\%)], Entamoeba coli [59 (14.6\%)], Blastocystis hominis [54 (13.3\%)], E. vermicularis [43 $(10.6 \%)]$, lodamoeba butschilii $\left[\begin{array}{lll}10 & (2.5 \%)\end{array}\right]$ and Hymenolepis nana [1 (0.2\%)], which infected primary school children. A total of 109 (26.9\%) students were infected with one parasite, 54 (13.3\%) with two parasites, $7(1.7 \%)$ with three parasites and $3(0.7 \%)$ with four parasites species.

The number of family members and education of parents' related prevalence of intestinal parasitic infections among primary school children is given in Table 1. Significant relation, observed in the education of parents and number of family members, is given in Table 2. The age prevalence of intestinal protozoan and intestinal parasitic infections are shown in Figures 1 and 2 , respectively.

\section{DISCUSSION}

The overall prevalence of intestinal parasites in Barandooz-Chay area of Urmia was $42.5 \%$, which was much lower than the prevalence in the rural area of Silvana $(52.6 \%)$, the southwest region of Urmia (Mostaghim et al., 2005). The results of the present investigation indicated that the total prevalence of intestinal protozoa infection was $31.6 \%$ among students of Barandooz-Chay area in Urmia and the prevalence of 


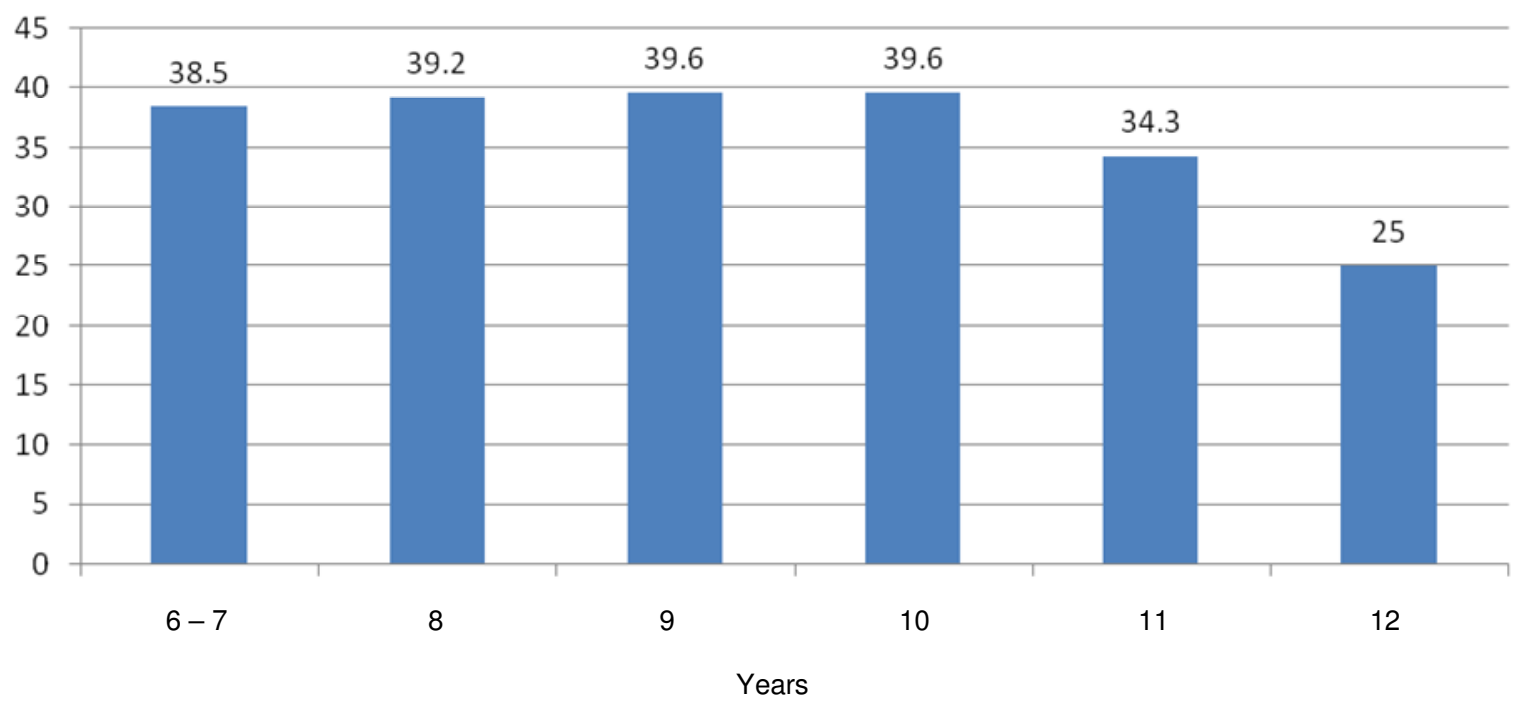

Figure 1. Age-prevalence of intestinal protozoan infections.

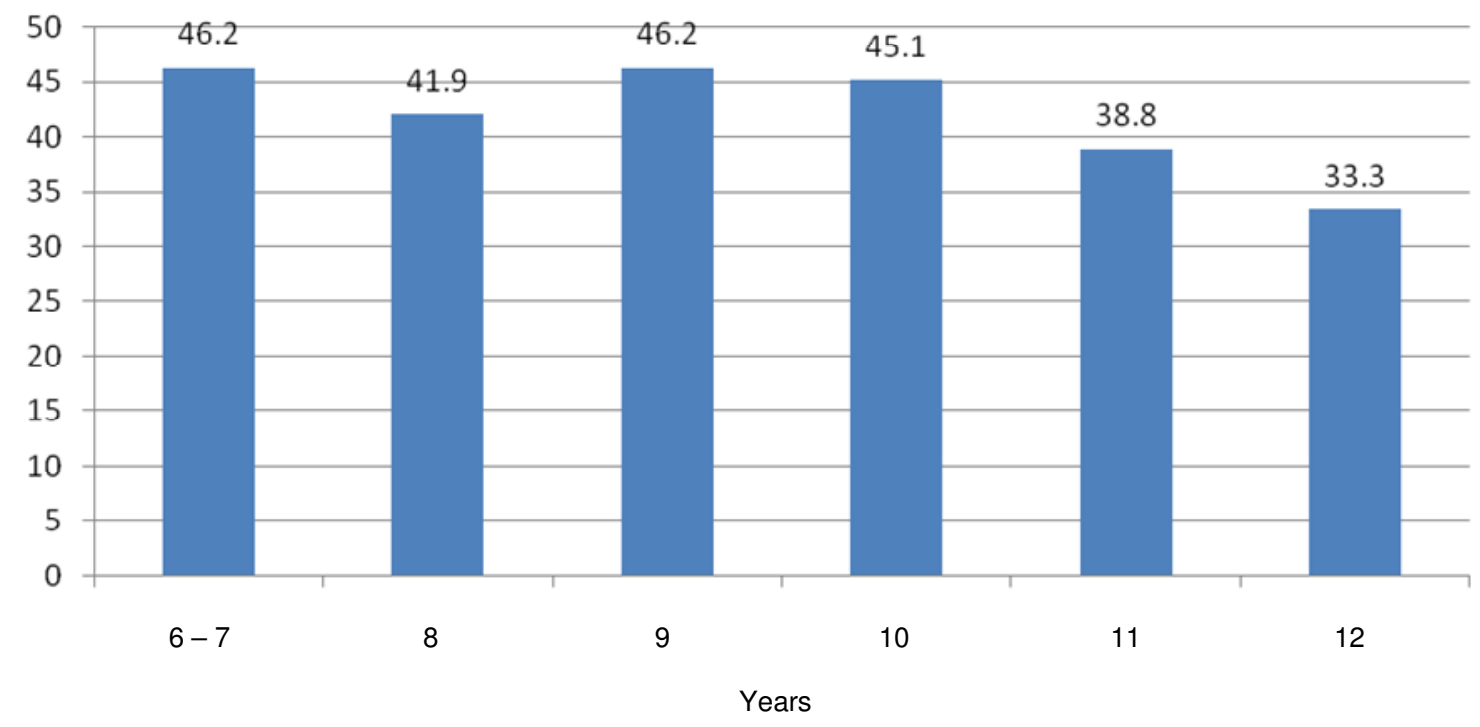

Figure 2. Age-prevalence of intestinal parasitic infections.

intestinal helminthes infection was $10.9 \%$ in the primary school children. The results of a study, which was completed by Hazrati Tappeh in 2005, showed that prevalence of protozoan infection was $28.4 \%$ in Nazloo (a region also in the Northwest part of Urmia). The prevalence of the protozoan parasites was $10.3 \%$ for $G$. lamblia and $10 \%$ for E. coli, being the two most common infections, as was observed in the Nazloo region in Urmia (Hazrati et al., 2006). A comparison of the prevalence indicated that $G$. lamblia with $20.5 \%$, E. coli with $14.6 \%$ and $B$. hominis with $13.3 \%$ were higher than other infections in Urmia, and this was estimated because the socioeconomic and environmental conditions were lower.
Abundance of helminthes infections was reported for $E$. vermicularis $(24.9 \%), H$. nana $(1.14 \%)$ and $A$. lumbricoides $(0.28 \%)$, by Mostaghim et al. (2005). Another study by Hazrati et al. (2006) reported infections for E. vermicularis $(28.4 \%)$ and $H$. nana $(0.4 \%)$, while the present study indicated infections for $E$. vermicularis $(10.6 \%)$ and $H$. nana $(0.2 \%)$. Low prevalence of $E$. vermicularis in this study might be due to the fact that the socioeconomic and environmental conditions were better. Several studies until 2004 in Hamadan city, west of Iran, have showed that prevalence of $A$. lumbricoides was higher, in comparison with other states. In those years, the mean infection rate of $A$. lumbricoides was $19.5 \%$ 
(Fallah et al., 2004). In this study, infection of $A$. lumbricoides was not reported in Barandooz-Chay, which was as a result of the avoidance of human fertilizers used by farmers. In 2004, Okyay et al. (2004) worked on the prevalence of intestinal parasites among primary school children in Aydin, a city in the western part of Turkey. The results showed that $145(31.8 \%)$ were infected with one or more intestinal parasites. The most common was $E$. vermicularis with $83(18.2 \%)$ infected children, the second was G. lamblia with $49(10.7 \%)$ infected children and the third was E. coli with $36(7.9 \%)$ infected children. In the present study, infection of protozoan, especially $G$. lamblia, is higher than helminthes infections.

The results of this study indicate high prevalence of some intestinal protozoa, especially G. lamblia, and a great amount of helminthes in the area. In contrast, based on the present study and other studies in various areas, the intestinal parasite infections in the world is one of the most important health indexes. In spite of its different prevalence in various societies and ages due to decrease or eradication, intestinal protozoan infections, especially giardiasis and amebiasis, are very important problems that societies are suffering from. High prevalence of $G$. lamblia in Barandooz-Chay region, in comparison with other parts of Iran, shows a necessity for more studies and a derivation of a solution for the problem.

\section{ACKNOWLEDGMENT}

The authors would like to thank the Vice-chancellor of Urmia University of Medical Sciences, Urmia-Iran, for financial support.

\section{REFERENCES}

Fallah M, Azimian MH, Nabiei M, Hojati M (2004). Epidemiological study of Ascariasis in Hamadan city, west of Iran, 2001. Sci. J. Hamadan Univ. Med. Sci., 11: 55-60.

Hazrati Tappeh KH, Mostaghim M, Khalkhali HR, Makooei A (2006). The prevalence of intestinal parasitic infection in the students of primary schools in Nazloo region in Urmia during 2004-05. Urmia Med. J., 16: 212-217.

Mostaghim M, Hazrati Tappeh KH, Khalkhali HR (2005). The prevalence of intestinal parasitic infection in the students of primary schools in Silvana region in Urmia during 2005. $4^{\text {th }}$ National Congress of Parasitic Diseases in Iran.

Okyay P, Ertug S, Gultekin B, Onen O, Beser E (2004). Intestinal parasites prevalence and related factors of parasitic infections in school children, a western city sample-Turkey. BMC Public Health., 4: $1-9$.

Scolari C, Torti C, Beltrame A, Matteelli A, Castelli F, Gulletta M, Ribas M, Morana S, Urbani C (2000). Prevalence and distribution of soiltransmitted helminth (STH) infections in urban and indigenous schoolchildren in Ortigueira, State of Parana, Brasil: implications for control. J. Trop. Med. Int. Health, 5: 302-307.

World Health Organization (1998). Control of Tropical Disease. Geneva. 